\title{
DEGENERATIVE CHANGES IN THE LEFT LOBE OF THE LIVER IN THE NEWBORN
}

\author{
BY \\ JOHN L. EMERY \\ From the Department of Pathology, Children's Hospital, Sheffield \\ (RECEIVED FOR PUBLICATION MAY 2, 1952)
}

The liver in a newborn child at necropsy occasionally shows a marked difference between the left and right lobes. The left lobe is darker in colour than the right and gives the impression of being shrunken. The division between the dark and light zones lies to the right of the anterior ligament and follows an irregular line from the inferior vena cava obliquely across the upper surface

Figs. 1 and 2.-Photographs of livers at necropsy showing dark discoloration and shrinkage of the left physiological lobe.

FIG. 3.-Photograph of the anterior edge of liver with unilateral congestion and degeneration showing the line of division between the affected and unaffected segments leading to the gall bladder. (approximately $\times 2$ ).

FIG. 1.

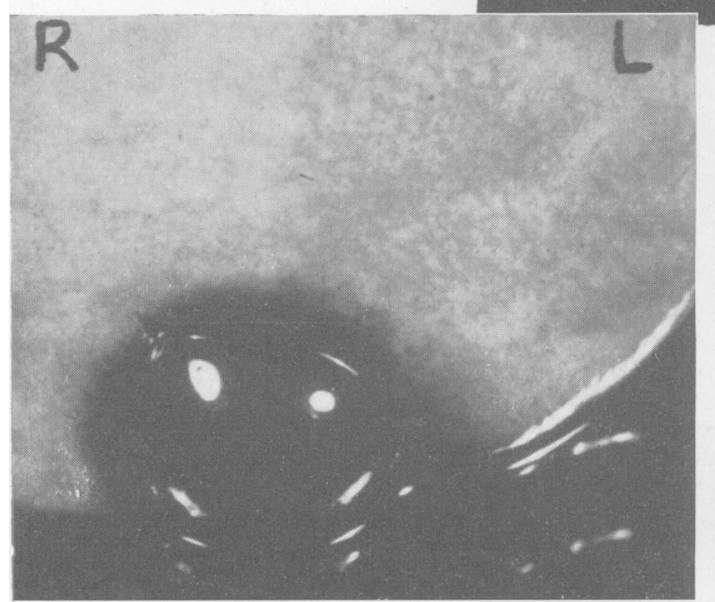

FIG. 3. of the liver to the tip of the gall bladder (Figs. 1, 2, and 3). This communication is concerned with the incidence and possible cause of this condition.
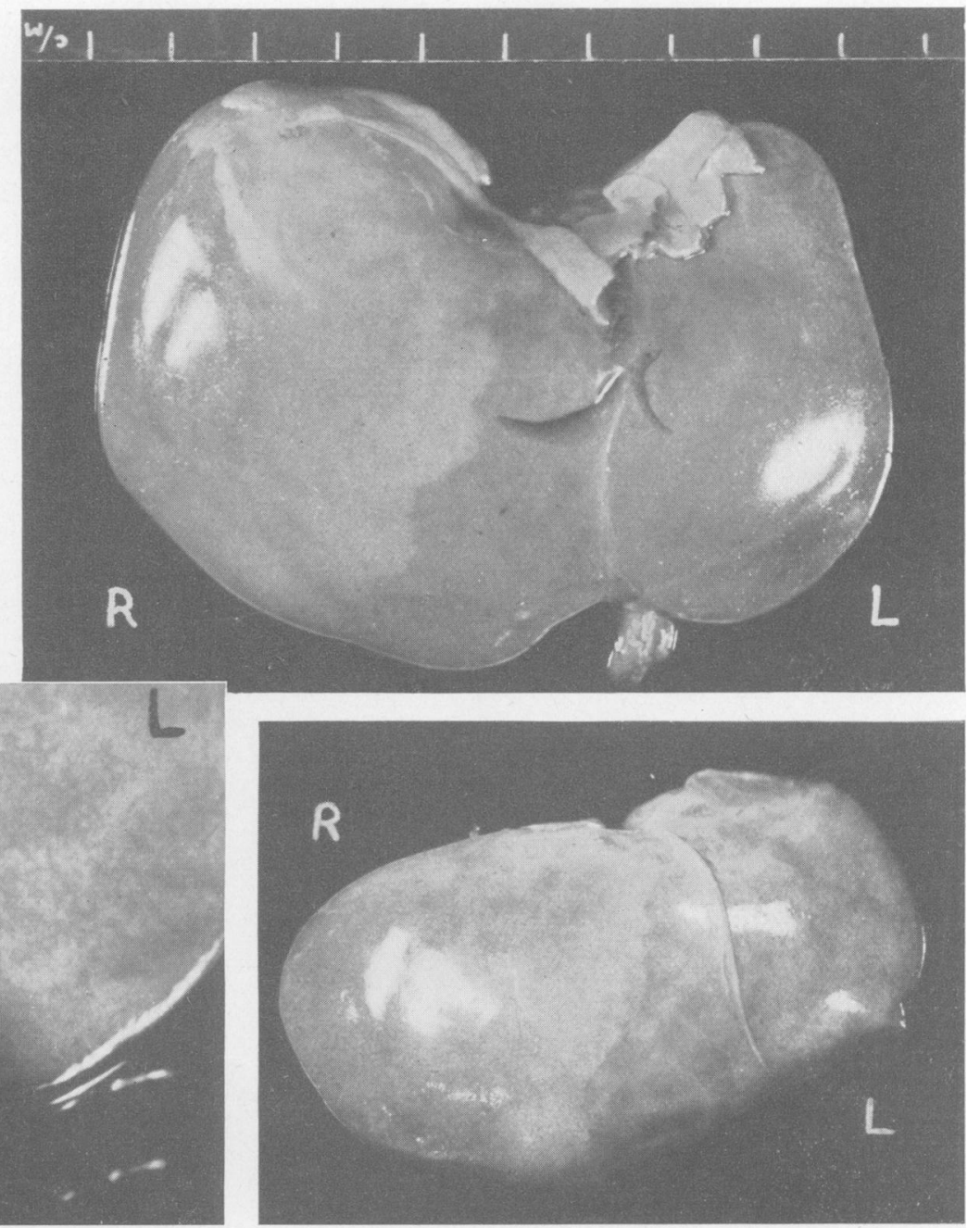

558

FIG, 2 . 
Material and Methods

The livers have been used from 110 consecutive and personally conducted necropsies carried out on children under the age of 2 months. Particular care was taken not to compress or disturb the liver during its removal from the body.

Blocks were taken from the left and right lobes in a set manner (Fig. 4) and carried through fixation and other processes together, the tissue from each side thus being a control for the other.
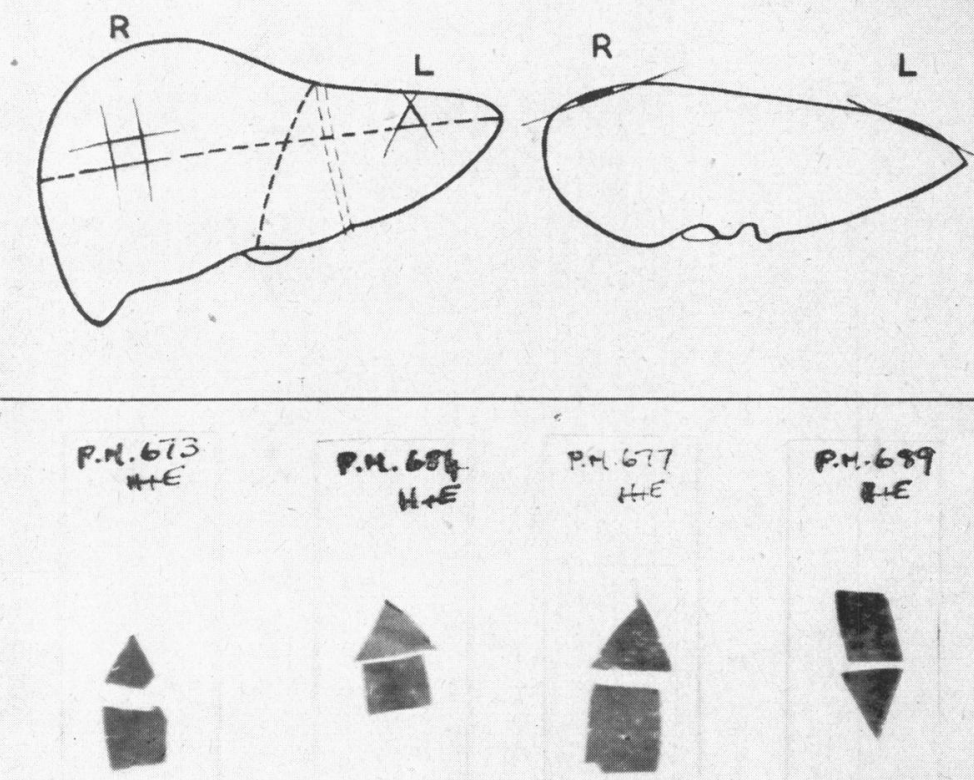

FIG. 4.-Diagram to illustrate the method of taking samples for microscopy from the liver and the method of mounting and identification of sections. groups are presented in Table 1. Fatty changes such as described by Gruenwald (1949) were seen but, not being considered relevant to the present discussion, are not recorded here.

None of the livers from the stillborn children showed asymmetrical degeneration but one showed generalized necrosis. In the other three age groups asymmetrical changes were marked, being most frequent in the first 48 hours, when 14 of 34 cases showed the lesion. In the next group, aged 3-14 days, five of 27 cases were found and in the older group three of 37 cases (Figs. 5 and 6).

In four of these 110 cases a marked naked eye difference between the two lobes of the liver was seen, the changes being much more obvious in the completely fresh material than after fixation. The line

' of division between the dark, shrunken segment and the rest of the liver followed an irregular line from the superior vena cava to the central point of the tip of the gall bladder (Figs. 1, 2 and 3).

Inadequate measurements of the ductus venosus were made in many cases and no attempt has been made to correlate the histological findings with the size of the ductus of the particular specimens.

In no case was thrombosis of the portal vein or hepatic vein found although many cases showed thrombosis elsewhere in the body.

TABLE 1

After staining the degree of hepatic cellular degeneration and shrinkage with associated sinus dilatation was assessed both absolutely and relative to the opposite side.

The findings were later correlated with the age and disease of the individual cases.

\section{Results}

The children were in the following age distribution: stillborn, 12; birth to 24 hours, 20 ; 25 hours to 48 hours, $14 ; 3$ days to 5 days, $15 ; 6$ days to 14 days, $12 ; 15$ days to 28 days, $18 ; 5$ weeks to 8 weeks, 19 . For simplification and analysis the first two days were grouped together, also the periods 3 to 14 days and 15 days to 18 weeks.

The histological findings in the different age 
(1906) the complete division of the liver into two physiological lobes distinct from the superficial anatomical difference has been universally recognized. The lesions seen in the livers of the newborn appear to coincide with the left physiological lobe, the line of division following the physiological division between the right and left livers.

The appearance of the livers in these children is very like that of the early changes produced by Rous and Larimore (1920) when they occluded a segment of the portal vein in rabbits. The lesion in the liver is also similar to the condition described

Figs. 5 and 6.-Photomicrographs showing the different microscopic appearances in the left and right lobes from two livers. (Haematoxylin and eosin $\because 70$.)

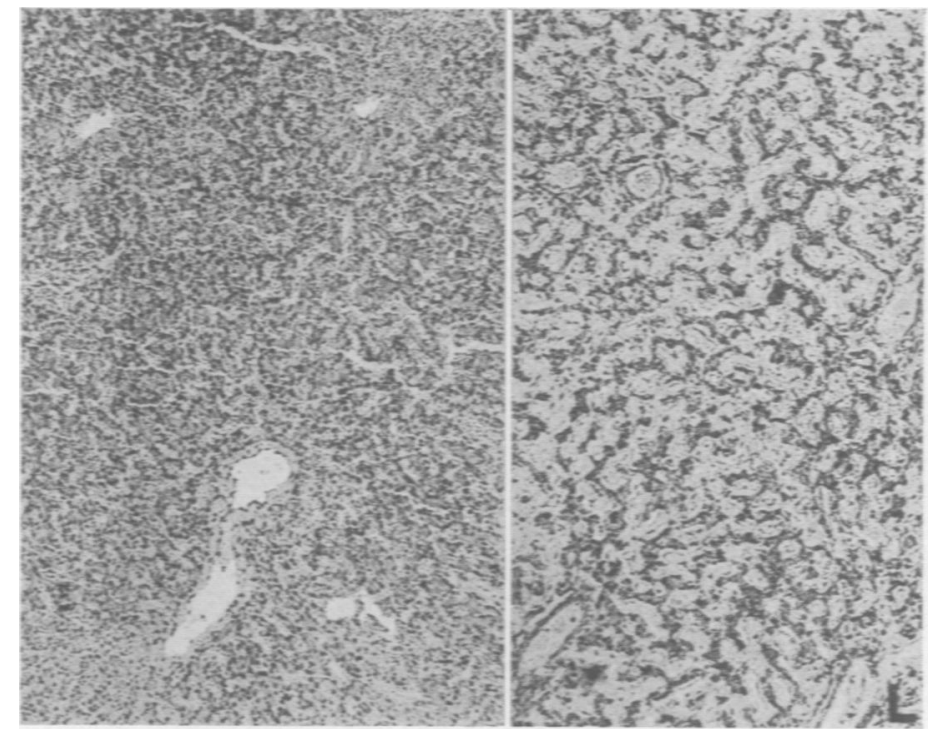

FIG. 5.

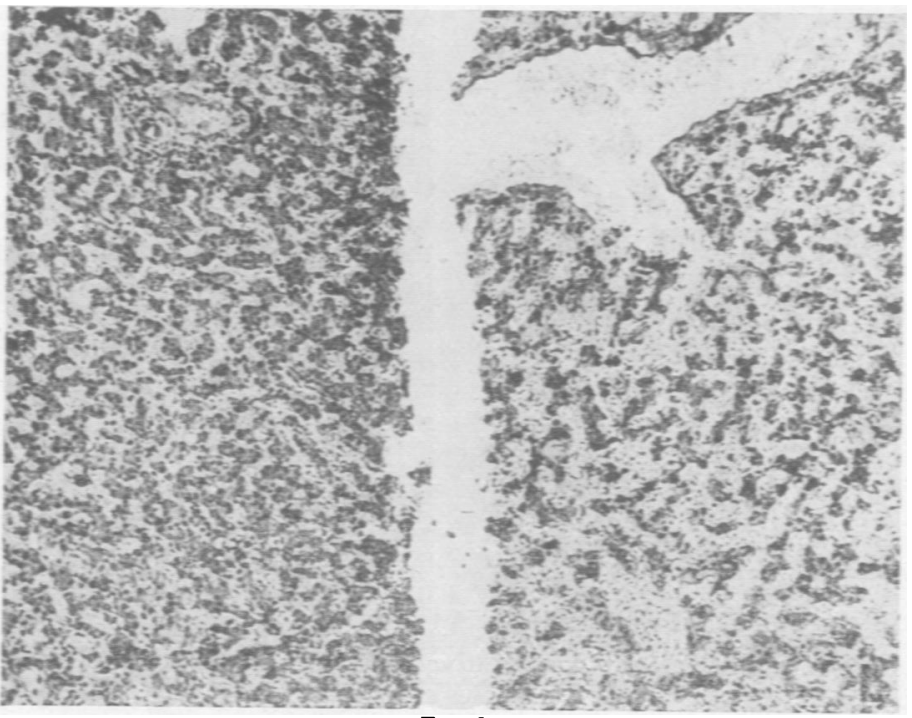

FIG. 6.

in the old German literature as the - atrophic red infarct of Zahn : and is again similar to changes seen in animals with an Eck fistula (Winternitz, 1911). Circulatory disorders producing such lesions in one lobe of the liver in adults have long been recognized (Wassink, 1915). All these lesions seem to be the result of disorder in the blood supply to the liver. In the present study it was not found in the stillborn infants and its greatest incidence was found immediately after birth, so it seems to be directly related to a vascular change occurring at birth.

Although the blood supply to the liver varies (Grindlay, Herrick and Mann. 1941), the liver cells are normally dependent for a considerable amount of their oxygen upon the portal venous supply, only about $40^{\circ}$ o coming from the hepatic artery (Markowitz and Rappaport, 1951).

The intra-hepatic circulation of venous blood at the time of birth is illustrated in Fig. 7. One notable feature is that the ductus venosus at the time of birth has a diameter of about one-seventh that of the umbilical vein (Barron, 1944). This implies that most of the blood from the placenta perfuses the left lobe of the liver; i.e., the left lobe of the liver receives the most highly oxygenated blood of the foetus. Immediately after birth the blood supply of the left lobe of the liver has to come from the portal vein. Thus the left lobe of the liver is subject at birth to a sudden gross diminution in the oxygen content of its circulating blood, a change which does not occur in the right liver.

It will also be obvious (Fig. 7) that the blood from the portal vein going to the left will only enter the left liver provided the blood is prevented from passing directly through the ductus venosus into 


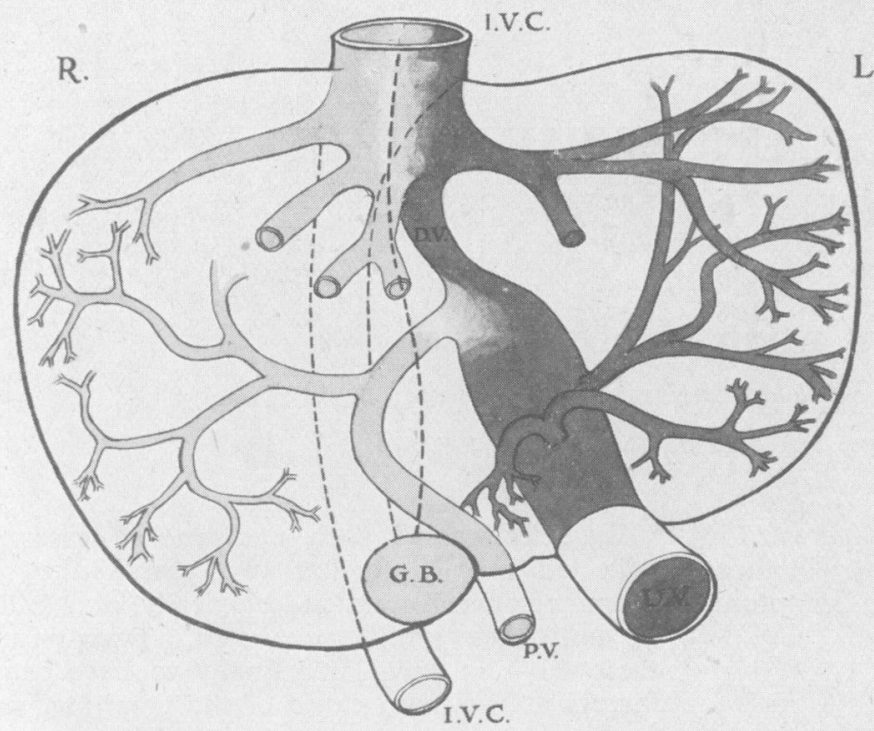

FIG. 7.-Diagram of the venous circulation of the liver at time of birth.

different parts of the portal tree is a well known factor in producing asymmetrical hepatic lesions in adults but it is difficult to see how this mechanism can be active at birth.

The question that arises concerning the liver degeneration is whether the condition is to be considered physiological and reversible or pathological. The high incidence of the condition in children who had otherwise adequate causes of death suggests that the condition is generally both physiological and reversible. It is possible that under conditions of circulatory upset or in an otherwise ill child it may be a contributory cause of death. The lesion may well be itself related to the

the inferior vena cava. Scammon and Norris (1918) showed that during the first eight days of life the ductus venosus was closed in only $2.3 \%$ of infants; that figure rose to $18 \%$ by 15 days to $37 \%$ by 22 days, to $75.7 \%$ by 32 days, and to $97.3 \%$ by the end of two months. The circulatory studies of Franklin, Barclay and Prichard (1940) and Barclay, Franklin and Prichard (1942) suggest that the necropsy appearance of a vessel like the ductus venosus will not necessarily indicate its degree of function during life. While taking this into consideration the possibility of a portal-caval shunt of a temporary nature at birth, i.e., a temporary physiological Eck fistula, cannot be ruled out, and such a condition would be expected o produce a change in the liver such as that seen in the left lobe in the present cases. Räihä (1941) showed that intravenous bilirubin is eliminated less readily in dogs with a Eck fistula, and he suggested that infantile icterus may be related to a transitory physiological fistula through the ductus venosus at birth. Clement Smith (1951) suggests that this feature merits consideration.

The parallel diminishing incidence of the degenerative changes in the left liver after birth and the patency of the ductus venosus may indicate a causal relationship but both are so closely related to birth that the coincidence may not be significant.

The lobular distribution in the liver of blood from production of physiological icterus.

\section{Summary}

Degeneration of parenchymal cells with dilatation of the sinusoids of the left lobe of the liver is described in the newborn.

The lesion was not seen in stillborn infants and was most common in children dying within 48 hours of birth.

The localization of the lesion to the left physiological lobe of the liver, the age incidence, and the associated incidence of patency of the ductus venosus suggest that the condition is associated with the great physiological circulatory changes in the left lobe of the liver which occur in the newborn at the time of birth.

The photographs were taken by A. K. Tunstill.

\section{REFERENCES}

Barclay, A. E., Franklin, K. J. and Prichard, M. M. L. (1942). Brit. , Radiol., 15, 66.

Barron, D. H. (1944). Physiol. Rev., 24, 277.

Franklin, K. J., Barclay, A. E. and Prichard, M. M. L. (1940). J. Anat., Lond., 75, 75.

Grindlay, J.' H., Herrick, J. F. and Mann, F. C. (1941). Amer. J. Physiol., 132, 489.

Gruenwald, P. (1949). Amer. J. clin. Path., 19, 801.

Mall, F. P. (1906). Amer. J. Anat., 5, 227.

Markowitz J. and Rappaport, A. M. (195i). Physiol. Rev., 31, 188.

Räihä, C. E. (1941). Acta paediat., Uppsala, 28, 390.

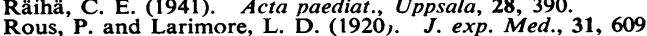

Rous, P. and Larimore, L. D. (1920, J. exp. Med., 31, 609.
Scammon, R. E. and Norris, E. H. (1918). Anat. Rec., 15, 165.

Smith, C. A. (1951). The Physiology of the Newborn Infant. 2nd ed., p. 81. Oxford.

Wassink, W. F. (1915). Ned. T. Geneesk., B., p. 2145.

Winternitz, M. C. (1911). Bull. Johns Hopk. Hosp., 22, 396. 